\title{
Esmolol attenuates hepatic blood flow responses during sodium nitroprusside-induced hypotension in dogs
}

[L'esmolol atténue la réaction du débit sanguin hépatique à l'bypotension induite par le nitroprussiate de sodium chez les chiens]

Shohei Takeda MD, Rikuo Masuda DD, Tatsuo Kanazawa MD, Teruaki Tomaru MD

Purpose: The hemodynamic responses secondary to sympathetic suppression by esmolol may alter blood flow to splanchnic organs. We investigated whether esmolol might modify splanchnic organ blood flow responses during sodium nitroprusside (SNP)-induced hypotension in dogs anesthetized with sevoflurane.

Methods: The control group $(n=10)$ received SNP (SNP group). The ES25 and ESI00 groups ( $n=10$, each) received SNP combined with esmolol infused at a constant rate of 25 and 100 $\mu \mathrm{g} \cdot \mathrm{kg}^{-1} \cdot \mathrm{min}^{-1}$ during the hypotensive period after a mean arterial pressure (MAP) of $60 \mathrm{mmHg}$ was attained by the infusion of a $0.03 \%$ SNP solution, respectively. The renal, hepatic, and pancreatic blood flows (RBF, HBF, and PBF) were measured by using the hydrogen clearance method.

Results: Cardiac index in the SNP group increased $(P<0.0$ I $)$, but in the ES groups it decreased $(P<0.0 \mathrm{I})$. Left ventricular $\mathrm{dP} / \mathrm{dtmax}$ in the SNP group remained unchanged, but in the ES groups it decreased $(P<0.01$, each) during the hypotensive period. Except for HBF in the SNP group, the splanchnic blood flow in all groups decreased $(P<0.01$, each). The HBF in the ES groups was lower than that in the SNP group (SNP vs ES25, ESI00; $70 \pm$ I vs $64 \pm$ $\left.5,63 \pm 3 \mathrm{~mL} \cdot \mathrm{min}^{-1} \cdot 100 \mathrm{~g}^{-1}\right)$.

Conclusions: This study shows that the differences in HBF between SNP-induced hypotension with or without esmolol may be due to the changes in cardiac output caused by alterations of cardiac contractility. These findings suggest that a small dose of esmolol may impair the maintenance of HBF during SNP-induced hypotension.
Objectif : Les réactions hémodynamiques secondaires à la suppression sympathique par l'esmolol peuvent modifier le débit du sang vers les organes splanchniques. Nous avons vérifié si l'esmolol pouvait modifier la réaction du débit sanguin des organes splanchniques à l'hypotension induite par le nitroprussiate de sodium (NPS) chez des chiens anesthésiés avec du sévoflurane.

Méthode : Le groupe témoin $(n=10)$ a reçu du NPS (groupe NPS). Les groupes ES25 et ESIO0 ( $n=10$, chacun) ont reçu du NPS combiné à une perfusion d'esmolol selon un débit constant de 25 ou 100 $\mu \mathrm{g} \cdot \mathrm{kg}^{-1} \cdot \mathrm{min}^{-1}$ pendant l'hypotension suivant la tension artérielle moyenne (TAM) de $60 \mathrm{mmHg}$ obtenue par la perfusion d'une solution de NPS à 0,03\%. Les débits sanguins rénal, hépatique et pancréatique (DSR, DSH et DSP) ont été mesurés par la méthode de clairance à l'hydrogène.

Résultats : L'index cardiaque a augmenté dans le groupe NPS $(P<$ $0,01)$, mais il a diminué dans le groupe $E S(P<0,01)$. La dP/dtmax ventriculaire gauche est demeurée inchangée dans le groupe NPS, mais a diminué dans les groupes ES ( $P<0,01$, chacun) pendant la période d'hypotension. Excepté pour le DSH dans le groupe NPS, le débit sanguin splanchnique a baissé dans tous les groupes $(P<0,0$ l chacun). Le DSH dans les groupes ES a été plus bas que celui du groupe NPS (NPS vs ES25, ESIO0; $70 \pm 1$ vs $64 \pm 5,63 \pm 3$ $\left.\mathrm{mL} \cdot \mathrm{min}^{-1} \cdot 100 \mathrm{~g}^{-1}\right)$.

Conclusion : L'étude montre que les différences de DSH entre l'hypotension induite par le NPS avec ou sans esmolol peuvent relever des changements de débit cardiaque amenés par des modifications de la contractilité cardiaque. Ces résultats suggèrent qu'une faible dose d'esmolol peut nuire au maintien du DSH pendant l'hypotension induite par le NPS.

From the Department of Anesthesiology, Showa University Fujigaoka Hospital, Yokohama, Japan.

Address correspondence to: Dr. Shohei Takeda, Department of Anesthesiology, Showa University Fujigaoka Hospital, 1-30 Fujigaoka,

Aoba-ku, Yokohama 227-8501, Japan. Phone: +81-45-971-1151; Fax: +81-45-973-1019; E-mail: showatakeda@hotmail.com

Accepted for publication June 18, 2003.

Revision accepted November 28, 2003. 


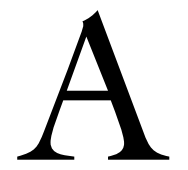

LTHOUGH sodium nitroprusside (SNP) is the most commonly used vasodilating agent for induced hypotension, it occasionally causes a hyperdynamic state secondary to reflex tachycardia, rebound hypertension elicited by activation of the sympathetic nervous and the renin-angiotensin systems, and cyanide toxicity due to overdose. ${ }^{1,2}$ These disadvantages of SNPinduced hypotension are attenuated by propranolol ${ }^{3,4}$ that possesses a relatively long half-life but might not be suitable for rapid control of the hemodynamic responses during SNP-induced hypotension.

Esmolol is a beta ${ }_{1}$-selective adrenergic receptor antagonist with a rapid onset and a short half-life ${ }^{5}$ that is effective in the management of the perioperative hemodynamic responses caused by sympathetic stim$\mathrm{uli}^{6,7}$ and is used as a primary agent to induce hypotension. ${ }^{8-10}$ However, esmolol-induced hypotension is known to have the potential for inducing a marked myocardial depression. ${ }^{11,12}$

SNP and esmolol differ in their abilities to alter the hemodynamic, sympathetic, and splanchnic organ blood flow responses to hypotension. ${ }^{13}$ In addition, the differences in pharmacological properties for the different hypotensive agents suggest that a combination of these agents may provide a pharmacological profile superior to either agent alone. ${ }^{12,14}$ The mechanisms by which SNP and esmolol-induced hypotension might alter splanchnic organ blood flow responses to hypotension remain to be elucidated. Because the hemodynamic and endocrine responses due to the sympathetic suppression caused by esmolol may alter blood flow to the splanchnic organs, this study was designed to determine whether two small doses of esmolol modify splanchnic organ blood flow responses during SNP-induced hypotension.

\section{Methods}

The study protocol was approved by the Animal Experimental Ethics Committee of Showa University Fujigaoka Hospital. Thirty healthy mature mongrel dogs of either sex weighing between 14 and $29 \mathrm{~kg}$ $(18.8 \pm 3.6 \mathrm{~kg}$, mean $\pm \mathrm{SD})$ were fasted overnight. Anesthesia was induced with sevoflurane $7 \%$ in oxygen administered in a sealed plastic induction chamber $(40$ $\times 85 \times 60 \mathrm{~cm})$. When the dogs became unconscious, they were removed from the induction chamber and the trachea was intubated. After tracheal intubation, the lungs were ventilated mechanically with a volumecycled animal ventilator (Model 613, Harvard Respirator, South Natrick, MA, USA) to maintain normocapnia. Anesthesia was maintained with $2.4 \%$ sevoflurane at a 1.0 minimum alveolar concentration via an Acoma sevoflurane vaporizer (Acoma, Tokyo, Japan) using oxygen as the carrier gas. End-tidal sevoflurane and $\mathrm{CO}_{2}$ concentrations were measured continuously by an infrared analyzer (Capnomac Ultima, Datex, Helsinki, Finland). The animals were given pancuronium bromide $\left(0.1 \mathrm{mg} \cdot \mathrm{kg}^{-1}, i v\right)$ to facilitate the experimental procedures.

Catheters were placed into the left femoral artery for continuous systemic blood pressure (SBP) monitoring and blood sampling, and into the right femoral vein for drug administration. Normal saline was infused at a rate of $7 \mathrm{~mL} \cdot \mathrm{kg}^{-1} \cdot \mathrm{hr}^{-1}$. A 7-F flow-directed pulmonary artery catheter (Swan-Ganz thermodilution catheter, Baxter Healthcare, Irvine, CA, USA) was advanced into the pulmonary artery via the right external jugular vein for measurement of right atrial pressure (RAP), pulmonary artery pressure, pulmonary capillary wedge pressure (PCWP), and cardiac output $(\mathrm{CO})$. The $\mathrm{CO}$ was measured by thermodilution using $5 \mathrm{~mL}$ of cold, temperature-monitored normal saline in triplicate. The results were recorded with a computerized system (MTC6210, Nihon Kohden, Tokyo, Japan). A 7-F catheter tipped transducer (Model SPC-370, Millar Instrument, Houston, TX, USA) was inserted through the right common carotid artery and positioned in the left ventricle to obtain left ventricular pressure, left ventricular end-diastolic pressure, and an instantaneous rate of change in the left ventricular pressure (left ventricu$\operatorname{lar} \mathrm{dP} / \mathrm{dt} \max )$ with the use of an electric differentiator (EG-601G, Nihon Kohden). Heart rate (HR) was obtained from lead II of the continuously monitored electrocardiogram (ECG) using a cardiotachometer (AT601G, Nihon Kohden, Tokyo, Japan). Each pressure catheter was connected to a pressure transducer (Uniflow, Baxter Healthcare, Irvine, CA, USA). The SBP and ECG were monitored continuously on a polygraph (RM6200, Nihon Kohden, Tokyo, Japan) and recorded with an eight-channel pen recorder (VM640G, Nihon Kohden, Tokyo, Japan). The dogs were immobilized in the supine position during the measurements, and the zero reference was levelled at the middle chest. Mean arterial pressure (MAP) and mean pulmonary artery pressure (MPAP) were determined electronically. Body temperature, monitored by the pulmonary artery catheter thermometer, was maintained at $37.0 \pm 1.0^{\circ} \mathrm{C}$ with electric heating pads and lamps. Arterial blood samples were drawn anaerobically from the femoral cannula. Arterial blood was analyzed for $\mathrm{pHa}, \mathrm{PaCO}_{2}, \mathrm{PaO}_{2}$, and base excess (BE) using a blood gas analyzer (Ciba-Corning 238, Chiron Diagnostics, MA, USA).

Following these preparations, a midline laparotomy was performed and the left kidney, liver, and pancreas 
TABLE I Changes in splanchnic organ blood flows before, during, and after SNP-induced hypotension with or without esmolol

\begin{tabular}{|c|c|c|c|c|c|c|}
\hline \multirow[t]{2}{*}{ Variables } & & \multirow[t]{2}{*}{ Baseline } & \multicolumn{2}{|c|}{ during Hypotension } & \multicolumn{2}{|c|}{ after Hypotension } \\
\hline & & & $30 \mathrm{~min}$ & $60 \mathrm{~min}$ & $30 \mathrm{~min}$ & $60 \mathrm{~min}$ \\
\hline $\mathrm{RBF}$ & SNP & $120 \pm 11$ & $112 \pm 10^{*}$ & $110 \pm 11$ ** & $117 \pm 10$ & $117 \pm 10$ \\
\hline \multirow{2}{*}{$\left(\mathrm{mL} \cdot \mathrm{min}^{-1} \cdot 100 \mathrm{~g}^{-1}\right)$} & ES25 & $126 \pm 8$ & $119 \pm 10^{*}$ & $115 \pm 11^{* *}$ & $122 \pm 7$ & $124 \pm 6$ \\
\hline & ES100 & $126 \pm 6$ & $117 \pm 9$ ** & $116 \pm 9 * *$ & $122 \pm 6$ & $123 \pm 5$ \\
\hline $\mathrm{HBF}$ & SNP & $69 \pm 3$ & $70 \pm 2$ & $70 \pm 1$ & $71 \pm 1$ & $71 \pm 2$ \\
\hline \multirow[t]{2}{*}{$\left(\mathrm{mL} \cdot \mathrm{min}^{-1} \cdot 100 \mathrm{~g}^{-1}\right)$} & ES25 & $70 \pm 2$ & $67 \pm 5^{*}$ & $64 \pm 5^{* *}+$ & $69 \pm 3$ & $70 \pm 2$ \\
\hline & ES100 & $71 \pm 3$ & $68 \pm 3^{*}$ & $63 \pm 3^{* *}+$ & $70 \pm 3$ & $71 \pm 3$ \\
\hline PBF & SNP & $38 \pm 3$ & $35 \pm 3^{*}$ & $35 \pm 3$ & $36 \pm 3$ & $37 \pm 3$ \\
\hline \multirow{2}{*}{$\left(\mathrm{mL} \cdot \mathrm{min}^{-1} \cdot 100 \mathrm{~g}^{-1}\right)$} & ES25 & $37 \pm 2$ & $35 \pm 2 * *$ & $35 \pm 1^{* *}$ & $36 \pm 1$ & $36 \pm 2$ \\
\hline & ES100 & $40 \pm 3$ & $37 \pm 6^{*}$ & $37 \pm 6^{*}$ & $38 \pm 6$ & $40 \pm 5$ \\
\hline
\end{tabular}

Values are mean $\pm \mathrm{SD} . \mathrm{RBF}=$ renal blood flow; $\mathrm{HBF}=$ hepatic blood flow; $\mathrm{PBF}=$ pancreatic blood flow. ${ }^{*} P<0.05 ;{ }^{*} P<0.01 v s$ baseline; $+P<0.05$ vs SNP.

were identified. Platinum electrodes (Standard needle type $100 \mu \mathrm{M}$ diameter, UHE-100, Unique Medical, Tokyo, Japan) were placed in the cortex of the left kidney, the left lobe of the liver, and the body of the pancreas. These platinum electrodes were introduced to a depth of 3 to $6 \mathrm{~mm}$ from the surface of the organs. Reference electrodes for the renal, hepatic, and pancreatic platinum electrodes were silver/silver chloride electrodes (Plate type UHE-001, Unique Medical, Tokyo, Japan) placed subcutaneously in the animal's flank close to the kidney, liver, and pancreas. The abdomen was then closed. The platinum electrodes were connected to hydrogen detection systems (Digital UH meter MHG-Dl, Unique Medical, Tokyo, Japan), and recorders (Desk recorder U-288, Unique Medical). Splanchnic organ blood flows were measured by using the hydrogen clearance method as described previously. ${ }^{15}$

The 30 dogs were divided into three groups: The ES25 and ES100 groups $(n=10$, each $)$ received esmolol 25 and $100 \mu \mathrm{g} \cdot \mathrm{kg}^{-1} \cdot \mathrm{min}^{-1}$ during the hypotensive period, respectively. The SNP group $(n=$ 10) received normal saline as control. After completion of surgical preparation, animals were observed at least $60 \mathrm{~min}$ to allow hemodynamic variables (SBP, MPAP, and HR) to stabilize. The baseline was measured before hypotension was induced. After baseline measurements, MAP was reduced to $60 \mathrm{mmHg}$ by the infusion of a $0.03 \%$ solution of SNP in all three groups. Esmolol was infused after the predetermined MAP was attained with the SNP solution. The hemodynamic variables were measured $15,30,45$, and 60 min during hypotension, and five, 15, 30, and $60 \mathrm{~min}$ after hypotension. The splanchnic organ blood flows and the arterial blood gases were measured every 30 min during and after hypotension.
Values are expressed as mean \pm SD. Hemodynamic variables and splanchnic organ blood flows for different time periods within a group were analyzed by ANOVA of the same variables followed post hoc by the Tukey's test. Intergroup comparisons (control group vs treatment groups) were analyzed by ANOVA of the same variables followed by Dunnett's test where appropriate. A $P<0.05$ was considered statistically significant.

\section{Results}

SNP administration in all groups was in a step-wise fashion until the predetermined MAP was attained. The hypotensive state was achieved within $6.7 \pm 1.8$ $\mathrm{min}$ in the SNP group, $5.6 \pm 1.5 \mathrm{~min}$ in the ES25 group, and $6.3 \pm 1.2 \mathrm{~min}$ in the ES100 group. The dose of SNP required to maintain the hypotensive state was $10.4 \pm 2.6 \mu \mathrm{g} \cdot \mathrm{kg}^{-1} \cdot \mathrm{min}^{-1}$ in the SNP group, $9.0 \pm 1.6 \mu \mathrm{g} \cdot \mathrm{kg}^{-1} \cdot \mathrm{min}^{-1}$ in the ES25 group, and $7.8 \pm$ $0.9 \mu \mathrm{g} \cdot \mathrm{kg}^{-1} \cdot \mathrm{min}^{-1}$ in the ES100 group.

The time course of splanchnic organ blood flow changes is shown in Table I. The renal blood flow $(\mathrm{RBF})$ decreased in all groups during the hypotensive period. The hepatic blood flow (HBF) in the SNP group remained unchanged throughout the experiment, but in the ES groups it decreased during the hypotensive period. The HBF was less in the ES groups than that in the SNP group at 60 min during the hypotensive period. The pancreatic blood flow $(\mathrm{PBF})$ decreased in the ES groups during the hypotensive period, but in the SNP group it decreased at 30 min during the hypotensive period.

The time course of hemodynamic changes is detailed in Tables II and III, available as Additional Material at www.cja-jca.org. MAP decreased in all groups during the hypotensive period but, in the SNP group, it remained depressed for 15 min after SNP 
was terminated. The HR remained unchanged in all groups during the hypotensive period, but in the ES100 group it remained decreased at $60 \mathrm{~min}$ after hypotension was terminated. The cardiac index increased in the SNP group, whereas in the ES groups it decreased during the hypotensive period. The stroke volume index increased in the SNP group, remained unchanged in the ES25 group, but decreased in the ES100 group during the hypotensive period. Left ventricular $\mathrm{dP} / \mathrm{dt} \max$ in the SNP group remained unchanged throughout the experiment, but in the ES groups it was reduced during the hypotensive period. RAP, MPAP, and PCWP decreased in all groups during the hypotensive period. The SVR decreased in all groups during the hypotensive period, but in the SNP group it remained depressed until $30 \mathrm{~min}$ after hypotension was terminated.

Changes of the arterial blood gas variables with time are presented in Table IV, available as Additional Material at www.cja-jca.org. The $\mathrm{PaCO}_{2}$ in the SNP group increased, but in the ES groups it remained unchanged throughout the experiment. The $\mathrm{PaO}_{2}$ in the SNP and ES25 groups remained unchanged throughout the experiment, but in the ES100 group it decreased during the hypotensive period. The BE decreased in all groups throughout the experiment but remained within normal limits.

\section{Discussion}

Our study shows that SNP-induced hypotension with or without esmolol resulted in a reduction in systemic vascular resistance associated with varying changes in $\mathrm{CO}$ resulting from the alterations in cardiac contractility. SNP-induced hypotension preserved $\mathrm{HBF}$ in the presence of a normal CO whereas SNP with esmolol resulted in reductions in $\mathrm{HBF}$ associated with a decreased CO.

The hemodynamic responses caused by SNP with esmolol imply that the beneficial properties of SNP may be masked by even small doses of esmolol. The effects of SNP-induced hypotension with esmolol on hemodynamic responses should be considered when these drugs are used clinically. SNP-induced hypotension with esmolol should not be used in patients with hypovolemia or heart failure, because it may exacerbate the decrease in $\mathrm{CO}$ and may be further aggravated by an esmolol-induced cardiac depression.

Splanchnic blood flow is regulated by intrinsic and extrinsic mechanisms. ${ }^{16}$ The extrinsic control of the hepatic circulation is regulated by $\mathrm{CO}$, arterial blood pressure, and sympathethic nervous activity. In addition, $\mathrm{HBF}$ is maintained by both hepatic arterial and portal venous flows; this hepatic circulation is regulat- ed by the hepatic arterial buffer response. ${ }^{17}$ Systemic hypotension may lead to a decreased portal venous flow, and subsequently to a decreased HBF. The maintenance of $\mathrm{HBF}$ associated with the significant decreases in PBF in the presence of increased CO during SNP-induced hypotension may reflect a compensatory increase in hepatic arterial blood flow, because a decrease in portal blood flow is reciprocally compensated by an increase in hepatic arterial blood flow. ${ }^{18,19}$ In contrast, the significant decreases in HBF during SNP-hypotension with esmolol were associated with a decreased PBF, most likely as a result of an esmololinduced cardiac depression. The mechanisms responsible for HBF reductions may reflect a redistribution of blood flow to the vital organs. The differences in HBF between the SNP and ES groups were due, probably, to the effects of esmolol on cardiac function, since SNP-induced hypotension with esmolol produced a more pronounced decrease in CO than did SNPinduced hypotension. In these conditions, the ability of the hepatic artery to increase $\mathrm{HBF}$ in response to decreases in portal blood flow may have been limited. Portal venous flow is determined by the arterial inflow resistance of the splanchnic organs. As a result, significant reductions in HBF were observed during SNPinduced hypotension with esmolol. Therefore, CO rather than arterial blood pressure may be proposed as a modulator of hepatic vascular tone and play a central role in the hepatic circulation during SNP-induced hypotension, because changes in hepatic plasma flow were linearly correlated to changes in cardiac index, but not to changes in MAP. ${ }^{20}$ These findings imply that the mechanisms of hepatic arterial buffer response may be well preserved with SNP-induced hypotension, but may be disrupted by esmolol. Although SNP-induced hypotension in a clinical study was suggested to produce a transient impairment of splanchnic perfusion and hepatocellular integrity during isoflurane anesthe$\mathrm{sia}^{21}$ the interaction between SNP and sevoflurane affected the hepatic circulation only slightly in this study. SNP-induced hypotension with esmolol produced hypoperfusion, but may not have increased the risk for ischemic liver damage, because the HBF was able to provide sufficient hepatic circulation to meet the oxygen demand, as revealed by arterial blood gas analyses. However, SNP-induced hypotension with esmolol should not be selected as the anesthetic of choice when reductions in $\mathrm{HBF}$ or deterioration in hepatic oxygenation are to be avoided.

RBF decreased equally during SNP-induced hypotension with or without esmolol in this study. It is more likely that the reductions in RBF in all three groups were due to hypotension beyond the normal 
range of renal autoregulation, because RBF intrinsically autoregulates with change in MAP from 80 to $180 \mathrm{mmHg}$ in dogs. ${ }^{22}$ In addition, SNP has only a weak vasodilating activity on the renal vasculature..$^{23,24}$ Because hypotension within the autoregulatory pressure range of the renal vasculature has been shown to result in redistribution of blood flow from the outer cortical layers to juxtamedullary layers ${ }^{25}$ mechanisms responsible for RBF reductions may cause a maldistribution of RBF within the autoregulation process. Although MAP recovered after induced hypotension was terminated, there were significant reductions in $\mathrm{RBF}$ in the ES groups. The possible explanation is that $\mathrm{RBF}$ reductions may be mediated by increases in plasma catecholamine concentrations and by augmentation of sympathetic nervous activity which may produce vasoconstriction of the renal arteries, because esmolol has been reported to increase plasma norepinephrine concentrations ${ }^{26,27}$ and beta-adrenergic receptor antagonist slows the clearance of norepinephrine from plasma. ${ }^{28,29}$

In conclusion, during sevoflurane anesthesia the reductions in HBF during SNP-induced hypotension with esmolol were due to the decrease in $\mathrm{CO}$ caused by the reductions in cardiac contractility. These findings suggest that small doses of esmolol may impair the maintenance of $\mathrm{HBF}$ during SNP-induced hypotension in dogs anesthetized with sevoflurane.

\section{Acknowledgements}

The authors thank Yoshie Hirakawa for her secretarial assistance. This research was supported in part by a Grant from Showa University, Tokyo, Japan.

Esmolol was provided by Maruishi Pharmaceuticals Co., Ltd, Osaka, Japan.

\section{References}

1 Bates J. Induced hypotension how and when. Curr Rev Clin Anesth 1988; 9: 50-5.

2 Friederich JA, Butterworth JF IV. Sodium nitroprusside: twenty years and counting. Anesth Analg 1995; 81: 152-62.

3 Bedford RF, Berry FA Jr, Longnecker DE. Impact of propranolol on hemodymanic response and blood cyanide levels during nitroprusside infusion: a prospective study in anesthetized man. Anesth Analg 1979; 58: 466-9.

4 Khambatta HJ, Stone JG, Matteo RS, Khan E. Propranolol premedication blunts stress response to nitroprusside hypotension. Anesth Analg 1984; 63: 125-8.

5 Sum CY, Yacobi A, Kartzinel R, Stampfli H, Davis CS, Lai CM. Kinetics of esmolol, an ultra-short-acting beta blocker, and of its major metabolite. Clin Pharmacol Ther 1983; 34: 427-34.

6 Menkhaus PG, Reves JG, Kissin I, et al. Cardiovascular effects of esmolol in anesthetized humans. Anesth Analg 1985; 64: 327-34.

7 Murthy VS, Hwang TF, Sandage BW, Laddu AR. Esmolol and the adrenergic response to perioperative stimuli. J Clin Pharmacol 1986; 26(Suppl A): A27-35.

8 Ornstein E, Matteo RS, Weinstein JA, Schwartz AE. A controlled trial of esmolol for the induction of deliberate hypotension. J Clin Anesth 1988; 1: 31-5.

9 Boezaart AP, van der Merwe J, Coetzee A. Comparison of sodium nitroprusside- and esmolol-induced controlled hypotension for functional endoscopic sinus surgery. Can J Anaesth 1995; 42: 373-6.

10 Pilli G, Güzeldemir ME, Bayhan N. Esmolol for hypotensive anesthesia in middle ear surgery. Acta Anaesth Belg 1996; 47: 85-91.

11 Ornstein E, Young WL, Ostapkovich N, Matteo RS, Diaz J. Deliberate hypotension in patients with intracranial arteriovenous malformations: esmolol compared with isoflurane and sodium nitroprusside. Anesth Analg 1991; 72: 639-44.

12 Blau WS, Kafer ER, Anderson JA. Esmolol is more effective than sodium nitroprusside in reducing blood loss during orthognathic surgery. Anesth Analg 1992; 75: 172-8.

13 Jordan D, Shulman SM, Miller ED Jr. Esmolol hydrochloride, sodium nitroprusside, and isoflurane differ in their ability to alter peripheral sympathetic responses. Anesth Analg 1993; 77: 281-90.

14 Edmondson R, Del Valle O, Shah N, et al. Esmolol for potentiation of nitroprusside-induced hypotension: impact on the cardiovascular, adrenergic, and reninangiotensin systems in man. Anesth Analg 1989; 69: 202-6.

15 Takeda S, Tomaru T, Inada $\Upsilon$. The effect of CGRPinduced hypotension on organ blood flow during halothane anesthesia in dogs: a comparison with trimetaphan. J Anesth 1997; 11: 202-7.

16 Granger DN, Richardson PD, Kvietys PR, Mortillaro $N A$. Intestinal blood flow. Gastroenterology 1980; 78: 837-63.

17 Lautt $W W$. Mechanism and role of intrinsic regulation of hepatic arterial blood flow: hepatic arterial buffer response. Am J Physiol 1985; 249: G549-56.

18 Lautt WW, Greenway CV. Conceptual review of the hepatic vascular bed. Hepatology 1987; 7: 952-63.

19 Doi R, Inoue K, Kogire M, et al. Simultaneous measurement of hepatic arterial and portal venous flows by transit time ultrasonic volume flowmetry. Surg Gynecol Obstet 1988; 167: 65-9.

20 Chauvin M, Bonnet F, Montembault C, Lafay M, Curet 
$P$, Viars $P$. Hepatic plasma flow during sodium nitroprusside-induced hypotension in humans. Anesthesiology 1985; 63: 287-93.

21 Suttner SW, Boldt J, Schmidt CC, Piper SN, Schuster P, Kumle B. The effects of sodium nitroprusside-induced hypotension on splanchnic perfusion and hepatocellular integrity. Anesth Analg 1999; 89: 1371-7.

22 Waugh WH, Shanks RG. Cause of genuine autoregulation of the renal circulation. Circ Res 1960; 8: 871-88.

23 Bastron RD, Kaloyanides GJ. Effect of sodium nitroprusside on function in the isolated and intact dog kidney. J Pharmacol Exp Ther 1972; 181: 244-9.

24 Pagani M, Vatner SF, Braunwald E. Hemodynamic effects of intravenous sodium nitroprusside in the conscious dog. Circulation 1978; 57: 144-51.

$25 \mathrm{McNay} J L$, Abe $\Upsilon$. Pressure-dependent heterogeneity of renal cortical blood flow in dogs. Circ Res 1970; 27: 571-87.
26 Ebert TJ, Bernstein JS, Stowe DF, Roerig D, Kampine $J P$. Attenuation of hemodynamic responses to rapid sequence induction and intubation in healthy patients with a single bolus of esmolol. J Clin Anesth 1990; 2: 243-52.

27 Thompson JP, West KJ, Hill AJ. The cardiovascular responses to double lumen endobronchial intubation and the effect of esmolol. Anaesthesia 1997; 52: 786-96.

28 Cryer PE, Rizza RA, Haymond MW, Gerich JE. Epinephrine and norepinephrine are cleared through beta-adrenergic, but not alpha-adrenergic, mechanisms in man. Metabolism 1980; 29: 1114-8.

29 Esler M, Jackman G, Leonard P, Skews H, Bobik A, Jennings $G$. Effect of propranolol on noradrenaline kinetics in patients with essential hypertension. $\mathrm{Br} \mathrm{J}$ Clin Pharmacol 1981; 12: 375-80.

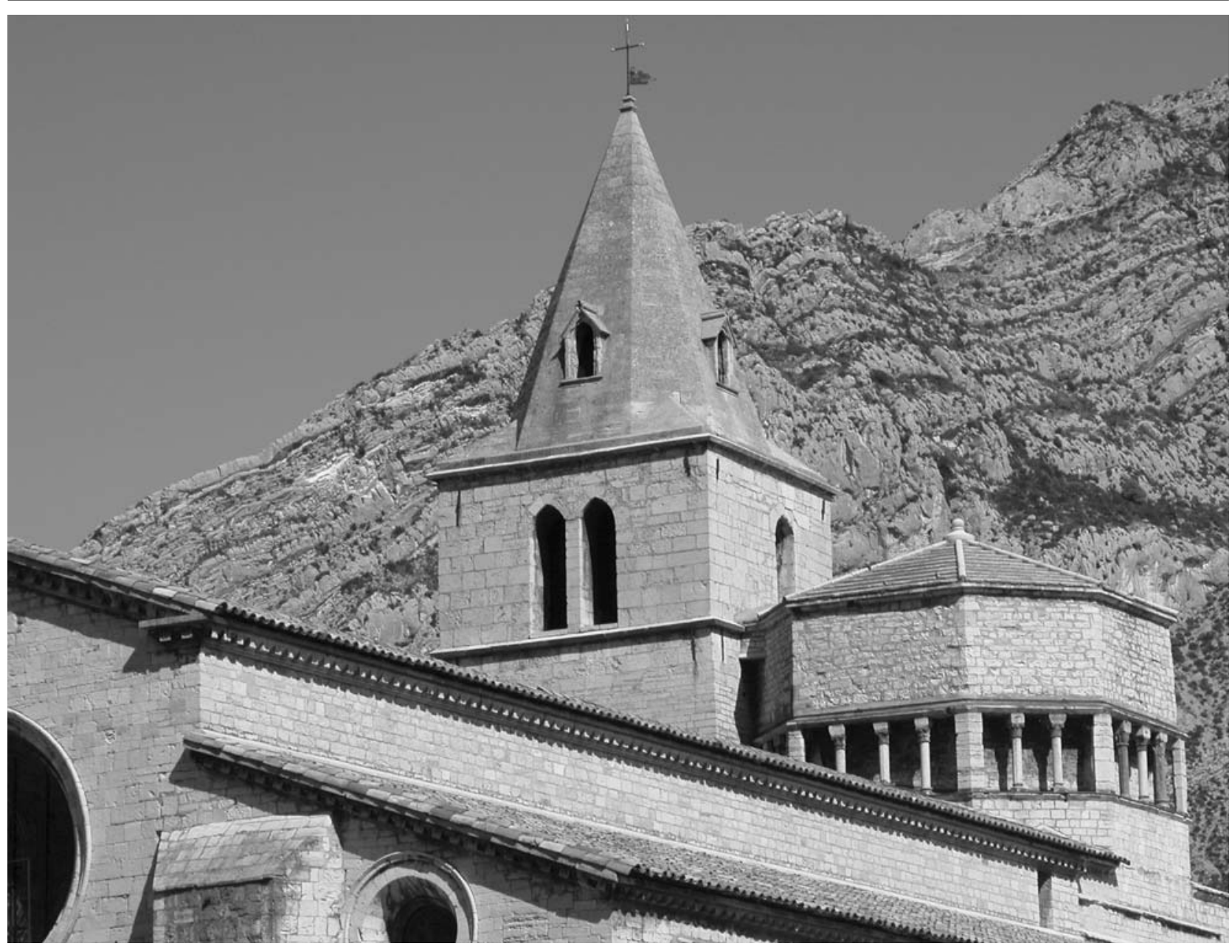

Église de Sisteron - France 